Revista Universo Contábil, ISSN 1809-3337
Blumenau, v. 14, n. 1, p. 07-28, jan./mar., 2018
doi:10.4270/ruc.2018101
Disponível em www.furb.br/universocontabil

\title{
TECNOLOGIAS NA EDUCAÇÃO: HÁ IMPACTO NO DESEMPENHO ACADÊMICO? ${ }^{1}$
}

\section{EDUCATION TECHNOLOGIES: THERE IMPACT ON ACADEMIC PERFORMANCE?}

\section{TECNOLOGÍAS EN LA EDUCACIÓN: ¿HAY IMPACTO EN EL DESEMPEÑO ACADÉMICO?}

\author{
Alexandre Costa Quintana \\ Doutor em Controladoria e Contabilidade da Universidade de São Paulo \\ Professor da Universidade Federal do Rio Grande \\ Rua Chefe Carlos Araújo, 166 - Rio Grande - RS \\ E-mail: professorquintana@hotmail.com \\ Telefone: (53) 9945-2132 \\ Luís Eduardo Afonso \\ Doutor em Economia da Universidade de São Paulo \\ Professor do PPG em Controladoria e Contabilidade da Universidade de São Paulo \\ Endereço: Av. Prof. Luciano Gualberto, 908 - Prédio FEA III - Butantã \\ CEP: 05.508-900 - São Paulo/SP - Brasil \\ E-mail: lafonso@usp.br \\ Telefone: (11) 3091-5920
}

\section{RESUMO}

O presente estudo tem como objetivo identificar o impacto do uso de duas tecnologias, chat e fórum de discussão, no desempenho acadêmico. Cada vez mais os estudantes utilizam e são atraídos pelo uso frequente de tecnologias, tendo como resultado grande fluência e versatilidade na sua aplicação. Portanto, é fundamental definir a maneira mais adequada de desenhar o processo de ensino de forma atraente para os estudantes. O referencial teórico está baseado na literatura sobre Tecnologias na Educação e Desempenho Acadêmico. Na essência, o estudo consistiu na realização de um experimento em uma turma da disciplina Contabilidade Introdutória de uma universidade federal, cuja principal diferença era o uso das tecnologias na educação, com o intuito de identificar os impactos do uso dessas tecnologias no desempenho dos estudantes. Os resultados do desempenho foram analisados utilizando teste de diferenças entre as médias de duas amostras com variâncias equivalentes. As tecnologias utilizadas foram o chat e o fórum de discussão. No grupo de tratamento, a intervenção caracterizou-se pelo fato de, além das atividades regulares da disciplina (adotadas no grupo de controle), terem sido

\footnotetext{
${ }^{1}$ Artigo recebido em 22/09/2016. Revisado por pares em 25/01/2018. Reformulado em 28/02/2018. Recomendado para publicação em 14/05/2018 por Tarcísio Pedro da Silva. Publicado em 20/12/2018. Organização responsável pelo periódico: FURB.
} 
empregadas as duas tecnologias. No início do semestre, os grupos foram definidos de forma aleatória, por meio de um sorteio. No início do segundo bimestre, os grupos foram invertidos: o grupo de tratamento passou a ser o de controle e vice-versa. Ao final, observou-se que o desempenho acadêmico pode ser aumentado com o uso das tecnologias. Os estudantes do grupo de tratamento tiveram uma variação positiva de 3,97 pontos na primeira etapa do experimento, enquanto que o grupo de controle teve uma variação de 2,69 pontos. Deve-se destacar ainda, que a variável idade afetou o desempenho dos estudantes.

Palavras chave: Tecnologia Educacional; Desempenho Acadêmico; Educação Contábil; Experimento.

\section{ABSTRACT}

This study aimed to identify the reflection of the use of two technologies, chat and discussion forum on academic performance. Increasingly, students use and are attracted by the frequent use of technologies, resulting in great fluency and versatility in application. Therefore, it is essential to define the most appropriate way to draw the attractive way learning process for students. The study consisted of an experiment in a class of Introductory Accounting discipline of a federal university, whose main difference was the use of educational technologies, in order to identify the impacts of the use of these technologies on student performance. The technologies used were chat and discussion forum. In the treatment group, the intervention was characterized by the fact that, in addition to regular course activities (adopted in the control group), have both been employed technologies. At the beginning of the semester, the groups were defined randomly by a draw. Early in the second quarter, the groups were reversed: the treatment group became the control and vice versa. At the end, it was observed that academic performance can be increased with the use of technology. Students in the treatment group had an increase of 3.97 points in the first stage of the experiment, whereas the control group had a variation of 2.69 points. It should also be noted that the age variable affecting student performance.

Keywords: Education technologies; Academic Achievement; Accounting Education; Experiment.

\section{RESUMÉN}

Este estudio tiene como objetivo identificar el reflejo del uso de dos tecnologías, chat y foro de discusión sobre el rendimiento académico. Cada vez más, los estudiantes utilizan y se sienten atraídos por el uso frecuente de las tecnologías, lo que resulta en gran fluidez y versatilidad en la aplicación. Por lo tanto, es esencial para definir la forma más adecuada para dibujar el proceso de aprendizaje de forma atractiva para los estudiantes. El estudio consistió en un experimento en una clase de disciplina introducción a la contabilidad de una universidad federal, cuya principal diferencia fue el uso de tecnologías educativas, con el fin de identificar los impactos del uso de estas tecnologías en el rendimiento de los estudiantes. Las tecnologías utilizadas eran foro de chat y la discusión. En el grupo de tratamiento, la intervención se caracteriza por el hecho de que, además de las actividades del curso regulares (adoptados en el grupo control), tienen ambas tecnologías empleadas estado. Al inicio del semestre, se definieron los grupos al azar por sorteo. A principios del segundo trimestre, se invirtieron los grupos: el grupo de tratamiento se convirtió en el control y viceversa. Al final, se observó que el rendimiento académico se puede aumentar con el uso de la tecnología. Los estudiantes en el grupo de tratamiento tuvo un incremento de 3,97 puntos en el primera etapa del experimento, mientras que el grupo de control tuvo una variación de 2,69 puntos. También hay que señalar que la variable edad que afecta el rendimiento de los estudiantes. 
Palabras clave: Tecnología Educacional; Rendimiento Académico; Contabilidad Educación; Experimento.

\section{INTRODUÇÃO}

O processo de ensino abrange um grande conjunto de eventos interativos e ações de professores e estudantes. Por isso, a preocupação com qualificação e melhorias nas práticas docentes deve ser fundamental para todos os professores. A utilização de tecnologias da informação nos cursos presenciais, na forma de tecnologias educacionais, representa uma forma de contribuir para o processo de aprendizado, que tradicionalmente se desenvolve com as atividades em sala de aula ou fora dela.

Neste sentido, as tecnologias podem ser usadas para criar diversas opções educacionais, com diferentes experiências de aprendizagem, que possibilitam aos estudantes descobrir e construir o conhecimento. Desta maneira, distância e aprendizagem online oferecem uma oportunidade não só para aumentar o alcance da educação, mas para melhorar a qualidade de ensino e aprendizagem (ABRAMI et al., 2011). Diversas técnicas podem ser utilizadas para a interação da tecnologia com a aprendizagem. O chat online, segundo McLeod, Dawson e Berg (2002), oferece a oportunidade para os estudantes esclarecerem e elucidarem questões dentro de um curto período de tempo, facilitando a comunicação com professores e colegas. Os fóruns de discussão permitem aos usuários postar seus temas e questões de aprendizagem. Os estudantes exercem muitas vezes o papel de solucionadores de problemas e o educador desempenha o papel de tutor ou mediador, observando como progride a aprendizagem. No papel de mediador, ele pode postar um problema, orientando, fornecendo dicas e sugestões para a solução ou, interativamente, juntar-se à discussão (CHIANG; FUNG, 2004).

De forma comparativa à educação tradicional, a aprendizagem online parece ser um caminho mais atrativo, por incentivar o interesse e a motivação, em virtude de o meio de interação ser mais familiar aos estudantes (CHEN; CHANG; WANG, 2008; CHOU; LIU, 2005). Assim, a combinação de fatores como motivação e interesse dos estudantes, planejamento e organização das instituições, conhecimento dos professores, e a forma de abordar o conteúdo, além da infraestrutura, garantem condições mínimas para o desenvolvimento de programas apoiados em ambiente educacional online (CORNACHIONE, 2004). Além disso, deve-se considerar que os estudantes são motivados quando acreditam ser capazes de sucesso em determinada tarefa, e quando entendem e valorizam o seu resultado (BROPHY, 2010). Essa motivação pode estar ligada ao meio atrativo proporcionado pelo uso da tecnologia em estudantes mais jovens. Carneiro, Toscano e Díaz (2009) afirmam que as gerações mais recentes de estudantes, que não passaram por um período de transição para as novas tecnologias acabam adquirindo o conhecimento de forma diferente da que ocorreu com as gerações anteriores, por meio do uso da tecnologia. Neste sentido, este trabalho se justifica, pois a geração de estudantes que hoje ingressa no ensino superior é, cada vez mais, composta por nativos digitais, ou seja, que são contemporâneos das novas tecnologias.

O pano de fundo do presente estudo é o contexto cada vez mais frequente, em que os estudantes utilizam e são atraídos pelo uso frequente de tecnologias, tendo como resultado grande fluência e versatilidade na sua aplicação. De acordo com Apostolou et al. (2016) os estudantes de contabilidade vêm tornando-se habilidosos no uso das tecnologias e os professores precisam explorar de formas eficazes a integração da tecnologia nos cursos de contabilidade e no processo de aprendizagem. A avaliação dos resultados da inserção de novas tecnologias é uma das áreas mais promissoras da literatura sobre educação contábil (APOSTOLOU et al., 2017). Portanto, é fundamental definir a maneira mais adequada de desenhar o processo de aprendizagem de forma atraente para os estudantes, sendo a tecnologia uma ferramenta de melhoria do desempenho acadêmico (ALDAMEN; AL-ESMAIL; 
HOLLINDALE, 2015; MORRIS et al., 2015). Desta maneira, o uso da tecnologia pode aprimorar o processo de aprendizagem e por consequência, a retenção de conteúdo (APOSTOLOU el al., 2016), e considerando o chat e o fórum de discussão como modalidades de interação de uso habitual. Define-se assim, a seguinte questão de pesquisa: qual o impacto do uso de chats e fóruns de discussão no desempenho acadêmico dos estudantes em um curso de graduação presencial de Ciências Contábeis? Desta forma, o estudo tem como objetivo identificar o impacto do uso de duas tecnologias, chat e fórum de discussão, no desempenho acadêmico.

Avalia-se que a contribuição do estudo esteja na utilização de um experimento para entender como a utilização de tecnologias, especialmente chat e fóruns de discussão, pode manter o processo de aprendizagem atraente e motivador para os estudantes, provocando reflexos no resultado do processo.

Esse trabalho está dividido em cinco seções. A primeira tratou da definição do objetivo de pesquisa e do contexto em que o tema está exposto. A segunda seção traz a revisão da literatura, focando principalmente, as tecnologias da educação. A seção seguinte descreve os procedimentos metodológicos. Por fim, as seções 4 e 5 apresentam, respectivamente, os resultados e as conclusões.

\section{TECNOLOGIAS NA EDUCAÇÃO}

Nos últimos anos tem ocorrido um crescente interesse no aproveitamento mais adequado dos meios virtuais para aumentar a eficiência e a eficácia da educação nos seus diversos níveis (SOIN, 2011). Assim, a tecnologia vem provocando mudanças no sistema de ensino. Um número crescente de instituições tem integrado a tecnologia no ambiente de aprendizagem para apoiar novas abordagens de ensino e melhorar o trabalho em equipe, em um esforço para reformar a educação (SCHRUM; LEVIN, 2010).

Olhando para o rápido desenvolvimento passado, bem como as perspectivas futuras, é seguro prever que a tecnologia irá continuar a melhorar e se tornar ainda mais amigável. Essas tendências influenciam a educação contábil fornecendo novas oportunidades para os professores repensarem a forma como eles ensinam sobre diferentes tópicos. Estes novos recursos podem aumentar a motivação dos alunos, aumentar o rigor e a profundidade do aprendizado, e envolver mais plenamente os estudantes em aprender sobre contabilidade através do uso da tecnologia (HOLTZBLATT; TSCHAKERT, 2011)

Assim, as tecnologias têm sido utilizadas como um instrumento de equalização de oportunidades. Este potencial inclui oportunidades para acessar materiais de alta qualidade a partir de locais remotos; a aprendizagem, independentemente da localização física do envolvido; o acesso à aprendizagem interativa; abordagens de aprendizagem flexíveis; desenvolvimento de serviços de aprendizagem para superar a situação de acesso limitado às informações; capacidade de avaliar e certificar a aprendizagem online e usar tecnologias para aumentar a eficiência. Além disso, possibilita gerar ações didático-pedagógicas implementadas pelos professores para promover experiências de aprendizagem diversificadas, e a possibilidade de uma aprendizagem independente permanente, em função das necessidades do estudante (SUNKEL, 2009).

O uso de Internet e tecnologias permite a interação estudante-professor ao vivo na classe, permite um contraste entre tecnologia e ensino presencial, em que o professor pode adicionar detalhes para solucionar dúvidas. Neste contexto, o produto final é dinâmico, os estudantes podem participar da produção de aulas expositivas e podem baixar as informações em qualquer lugar e em qualquer momento em um telefone celular, computador, televisão ou outro dispositivo eletrônico (SAVAGE, 2009).

Conforme Atif (2012) os estudantes universitários são considerados nativos digitais, pois cresceram em meio à tecnologia. No entanto, apesar de ter havido uma evolução 
multidimensional com os discentes, nas salas de aulas, que é o local em que se constrói a experiência de ensino, poucas mudanças ocorreram. Atif (2012) realizou um experimento, concebendo um ambiente de sala de aula com base em um leiaute de tecnologia avançada, incluindo uso de quadro interativo, tablet, painel de controle para o professor, unidade telepresencial, tela touch screen e células/grupos de trabalho. Os resultados sugerem que o resultado da aprendizagem foi melhor em relação ao modelo de aprendizagem convencional, na sala de aula tradicional.

No intento de promover melhorias no processo de ensino, Abrami et al. (2011) exploraram três tipos de interação: entre os alunos; entre o professor e os alunos; e entre os alunos e o conteúdo do curso. Os autores abordaram desafios pedagógicos inerentes ao ensino à distância e a aprendizagem online, destacando que o esforço para favorecer as interações estudadas inclui a dedicação de pesquisadores, designers, engenheiros de computação e professores. A próxima geração do ensino a distância, segundo os autores, deve ser mais bem concebida para facilitar a interação. Várias abordagens teóricas e empíricas são úteis neste intento, tais como os princípios de aprendizagem autorregulada, os princípios de aprendizagem multimídia, os princípios de design motivacional, e os princípios de aprendizagem cooperativa e colaborativa.

A aplicação das tecnologias da educação pode ampliar o interesse do aluno na aprendizagem. Soin (2011) estudou a motivação dos estudantes de ensino superior com a aprendizagem. $\mathrm{O}$ autor destaca que muitos estudantes necessitam de seus professores para se inspirarem e para se sentirem desafiados. Assim, o professor deve ter capacidade para manter o interesse do aluno e efetivar a aprendizagem, pois o nível de motivação varia conforme os acontecimentos da sala de aula. $\mathrm{O}$ autor acrescenta que nem todos os alunos são motivados pelos mesmos valores, necessidades, desejos ou vontades. Alguns são motivados pela aprovação, outros pela superação de desafios. Os resultados da pesquisa evidenciam aspectos da situação de ensino que melhoram a automotivação dos alunos, dentre estes estão boas práticas pedagógicas cotidianas, bem como tecnologias de informação e comunicação, que podem contribuir para combater a apatia do estudante.

Para Jena (2011) o cenário tecnológico mundial tem pavimentado o caminho para novas pedagogias no processo de ensino-aprendizagem com foco no ambiente de aprendizagem baseado em tecnologia e seu impacto sobre o desempenho do aluno. Jena (2011) realizou um estudo experimental para determinar a eficácia do ambiente de aprendizagem baseado em tecnologia no desempenho dos alunos em inglês como língua estrangeira. Os resultados da pesquisa evidenciaram que há diferença significativa entre os escores médios dos grupos de tratamento e de controle. Ou seja, o ensino e a aprendizagem através de tecnologias na educação podem ser adotados para aumentar a capacidade de aprendizagem da língua dos alunos.

Zhao et al. (2005) constataram que, em estudos de ensino à distância, aplicações que combinam comunicação síncrona e assíncrona tendem a gerar mais efeitos positivos do que aplicações com apenas uma destas interações. Ao focar a comunicação no ambiente assíncrono, Cornachione et al. (2012) destacam um componente importante da educação online que seria importante investigar - formas específicas com que os novatos e profissionais experientes tendem a se relacionar com seus pares e com o instrutor - e o conteúdo de temas específicos. Neste sentido, o uso de duas formas de interação torna-se necessário para que ocorra comunicação síncrona (chat) e assíncrona (fórum), visto que Zhao et al. (2005) indicam a possibilidade maior de resultados positivos.

No estudo de Aldamen, Al-Esmail e Hollindale (2015) foi investigado o efeito do uso de palestras gravadas no desempenho do curso para estudantes de primeiro ano $(n=254$, taxa de resposta de 100\%) matriculados em uma disciplina do curso de contabilidade em uma universidade no Catar. Eles identificaram que o desempenho dos alunos foi significativamente positivo associado ao número de vezes que as palestras gravadas foram vistas. Estudantes 
relataram que as palestras gravadas eram uma ferramenta de aprendizado benéfica e aumentaram seu interesse pelo curso.

Morris et al. (2015) examinaram se o uso de uma pedagogia baseada em tecnologia afetou o desempenho dos alunos em um curso introdutório de contabilidade financeira. O estudo realizado em uma universidade pública dos EUA dividindo os estudantes em dois grupos, um de controle ( $n=118$ alunos) e outro de tratamento $(n=64$ alunos). Os alunos do grupo de controle seguiram a pedagogia tradicional, que se concentrou em aulas expositivas e resolução de problemas. Os alunos do grupo de tratamento utilizaram uma plataforma de instrução online com palestras mínimas em sala de aula. Foram realizadas três provas no curso e a variável dependente em vários modelos de regressão foi a mudança no desempenho da prova. O uso de uma pedagogia baseada em tecnologia foi significativamente positiva associada ao desempenho ao longo da disciplina.

Desta forma, observa-se que de forma geral, os estudos indicam um melhor desempenho em função do uso das tecnologias. No entanto, observa-se que em algumas situações a tecnologia não provoca efeitos, como exposto no estudo de Khanlarian e Singh (2015) que examinaram se o uso de softwares baseados na web afeta a percepção dos estudantes sobre o uso e o desempenho da tecnologia em provas e exames. Estudantes online $(\mathrm{n}=111)$ e estudantes presenciais $(n=257)$ da fase inicial de uma importante universidade sudeste dos Estados Unidos usaram software baseado na web, para realizar tarefas em casa. Estudantes online e presenciais apresentaram níveis similares de frustração com o software. Não foram encontradas diferenças significativas entre estudantes online e presenciais com relação a utilidade, auto-eficácia e eficácia técnica percebida no uso da tecnologia.

Neste sentido, reforçasse a importância do presente estudo, qual seja, verificar o impacto do uso da tecnologia no desempenho acadêmico, pois apesar de haver uma maior quantidade de estudos que indicam o efeito positivo, ainda observasse que dependendo da situação o uso da tecnologia, não provoca efeito no desempenho em provas e exames dos estudantes.

\subsection{Desempenho Acadêmico}

A cultura de avaliação precisa ser permanentemente aprimorada e envolve as lideranças, professores e estudantes, para trabalharem em conjunto no desenvolvimento de objetivos e definição de critérios. A avaliação fornece feedback útil para todos, que pode ser usado para melhorar a aprendizagem, tanto pelos professores, como pelos estudantes (HAVNES et al., 2012). A avaliação contribui para aperfeiçoar a eficácia da didática e dos recursos pedagógicos utilizados, favorecendo a tomada de decisões no decorrer do processo de ensino-aprendizagem, com o objetivo de melhorar a qualidade do conhecimento que se está desenvolvendo (LUCKESI, 2005).

Como forma de responder a essas demandas, são desenvolvidos inúmeros programas de avaliação para que se possa mensurar a qualidade de um curso ofertado, ou da própria IES. Hou (2013) explorou as diferenças comportamentais entre estudantes considerando a diferença de gêneros, o conhecimento prévio (alto/baixo) e o desempenho na aprendizagem (alto/baixo), no contexto da massively multiplayer online role-playing games. Em seu estudo, Hou (2013) tratou a nota obtida pelo estudante no semestre anterior como sendo o conhecimento prévio do acadêmico e a nota atual como sendo o desempenho na aprendizagem. Já Aldamen e Duncan (2013) exploraram o efeito que o envolvimento de estudantes em quizzes realizados via web trouxe sobre o seu desempenho na disciplina de contabilidade intermediária, considerando também, as notas obtidas pelos discentes.

No ambiente online, uma alternativa para medir as formas de avaliação é concentrar-se em questões de processo, em vez de produto. Esse enfoque vai, de alguma forma, no sentido de resolver o problema de inferir o desempenho dos estudantes. Onde as estratégias orientadas para processos de avaliação estão mais bem definidas, percebe-se uma perspectiva nova e 
importante para a avaliação. Em vez de as alterações no processo serem um problema para o estudo, elas se tornam o foco do estudo (OLIVER; HARVEY, 2002).

Neste sentido, a combinação de tecnologias da educação com o processo de ensino, por meio de alternativas complementares, pode gerar reflexos no aprendizado, em um ambiente onde o estudante conta com mais facilidades e habilidades, e que serve de elemento para sua motivação e consequente melhoria do desempenho. Com isso, envolve-se o professor em um processo de ajuste na sua forma de atuar para atingir o objetivo de levar o conhecimento e a informação ao estudante.

\section{PROCEDIMENTOS METODOLÓGICOS}

A pesquisa foi feita no primeiro semestre de 2015 em uma universidade federal, em um curso totalmente presencial. Os participantes foram os estudantes do primeiro semestre do curso de Ciências Contábeis matriculados na disciplina Contabilidade Introdutória no período noturno. Antes do início do semestre a turma foi dividida de forma aleatória em dois grupos, compondo duas turmas distintas, definidos como de tratamento (GT) e de controle (GC), sendo que o primeiro, além das atividades regulares da disciplina, experimentou as interações tecnológicas. A distribuição dos estudantes nos grupos, foi feita por meio de um sorteio. Este procedimento teve por objetivo promover a distribuição aleatória dos dois grupos, o que significa que cada unidade de amostragem tem uma chance igual de estar em cada condição experimental (FRIEDMAN; SUNDER, 1994). As aulas para ambos os grupos foram ministradas pelo mesmo professor. Desta forma, seguindo as recomendações de List, Sadoff e Wagner (2011), procurou-se controlar o maior número de fatores que pudessem afetar os resultados decorrentes da intervenção realizada.

Figura 1 - Desenho experimental

\begin{tabular}{|lllll|}
\hline $\mathbf{1}^{\circ}$ bimestre & \multicolumn{1}{l|}{} & \\
\hline Grupo de tratamento & $\mathrm{R}$ & $\mathrm{O}$ & $\mathrm{X}$ & $\mathrm{O}$ \\
\hline Grupo de controle & $\mathrm{R}$ & $\mathrm{O}$ & $\mathrm{O}$ \\
\hline $\mathbf{2}^{\circ}$ bimestre & & & & $\mathrm{O}$ \\
\hline Grupo de controle & $*$ & $\mathrm{O}$ & $\mathrm{O}$ & \\
\hline Grupo de tratamento & $*$ & $\mathrm{O}$ & & \\
\hline $\begin{array}{l}\mathbf{R}=\text { distribuição aleatória dos grupos (sorteio) } \\
\mathbf{O}=\text { mensuração do desempenho (provas inicial e final) } \\
\mathbf{X}=\text { tratamento experimental (chat e fórum de discussão) } \\
* \text { No 2 } \mathbf{2}^{\circ} \text { bimestre, os grupos de tratamento e controle foram invertidos em relação ao 1 }{ }^{\circ} \text { bimestre }\end{array}$ \\
\hline
\end{tabular}

Fonte: Elaborado pelos autores.

O desenho experimental está exposto na Figura 1. O experimento teve duração de um semestre letivo, composto por dois bimestres. No primeiro dia do semestre foi aplicada uma prova inicial, para avaliar o conhecimento inicial de ambos os grupos e servir como referência para a prova aplicada no final do semestre. Também foi aplicado um questionário sobre o perfil dos alunos. Em cada bimestre foram utilizados no GT um fórum de discussão e dois chats. Os fóruns e os chats serviram para compor um ambiente de aprendizagem interativo, e foram escolhidos por representar formas de abordagens diferentes: uma síncrona (chat) e a outra assíncrona (fóruns). Além disso, são meios de interação acessíveis aos estudantes, independentemente do local e equipamento que eles utilizem, e também são opções sobre as quais o professor pode manter maior controle quanto à participação discente. No início do segundo bimestre, os grupos foram invertidos. Ou seja, o GT do primeiro bimestre passou a ser 
GC, e o GC do primeiro bimestre passou a ser GT. Isto foi feito para que nenhum aluno fosse prejudicado, por não ter acesso às ferramentas de interação tecnológica. Todos os estudantes assinaram termo de consentimento concordando em participar do experimento. Durante a realização do experimento, o pesquisador acompanhou o andamento de forma virtual, por meio do sistema Moodle (Modular Object-Oriented Dynamic Learning Environment). Além das interações tecnológicas, o Moodle foi o sistema de apoio empregado para o gerenciamento do conteúdo e das demais atividades desenvolvidas.

Desta forma, a realização do experimento contou com as etapas:

$>$ antes do início do semestre: divisão da turma nos Grupos de Tratamento (GT) e de Controle (GC), de forma aleatória.

$>$ primeiro dia de aula: aplicação de prova inicial e de questionário sobre o perfil dos alunos.

$>$ durante o $1^{\circ}$ bimestre: utilização dos dois chats e do fórum de discussão no GT.

$>$ final do $1^{\circ}$ bimestre: aplicação de prova intermediária para ambos os grupos.

$>$ final do $1^{\circ}$ bimestre: troca dos grupos, ou seja, o grupo de tratamento do 10 bimestre passou a ser o grupo de controle no 2o bimestre, e este passou a ser o grupo de tratamento. Análise comparativa do desempenho dos grupos entre a prova inicial e final, e entre os bimestres.

$>$ durante o $2^{\circ}$ bimestre: utilização dos dois chats e do fórum de discussão no novo GT.

$>$ final do $2^{\circ}$ bimestre: aplicação de prova final para ambos os grupos.

O conteúdo e as atividades desenvolvidas nas turmas foram os mesmos, sendo a única diferença entre os grupos o uso das tecnologias. Não foram atribuídas notas específicas para a participação nos chats e fóruns.

Para analisar o conhecimento inicial dos estudantes foram aplicados testes de médias para identificar se havia diferença entre o desempenho dos grupos. Ou seja, tem-se um experimento controlado, com procedimento de aleatorização entre os participantes dos grupos, em que o tratamento é dicotômico (emprego de chats e fóruns) e a variável de resultado é contínua (a nota nas provas), conforme apresentado por List, Sadoff e Wagner (2011). Para todos os testes apresentados no decorrer deste trabalho, adotou-se o nível de significância de $5 \%$. Os testes foram realizados no software Stata.

A estatística do teste de hipótese para duas médias de amostras independentes é a distribuição $\mathrm{t}$, em que representam, respectivamente, a média dos valores observados na primeira e segunda amostras; correspondem à média da primeira e da segunda população; e, a variância da primeira e da segunda amostra; representam o número de observação da primeira e segunda amostras (TRIOLA, 2005).

\section{RESULTADOS}

Nesta seção são descritos os resultados do experimento. Inicialmente são apresentadas as características dos estudantes. Na sequência são reportados os resultados das avaliações de cada bimestre, para cada grupo.

\subsection{Características dos grupos}

Com o início das aulas, foi possível precisar o número de estudantes que realmente iriam frequentar a disciplina, pois é possível que alguns estudantes se matriculem mas não frequentem as aulas. Desta forma, o grupo de tratamento ficou com 34 estudantes e o grupo de controle com 32 estudantes. 
Os grupos foram formados basicamente por estudantes ingressantes. Na primeira semana de aulas foi explicado aos estudantes dos dois grupos que seria realizado um estudo, do qual eles fariam parte, e para isso seria necessário que assinassem um termo de concordância. Não houve nenhuma recusa por parte dos alunos. De acordo com os procedimentos metodológicos, foi realizada uma prova inicial, que teve duração aproximada de 30 minutos em cada turma, contendo dez questões de múltipla escolha. Os resultados são apresentados na Tabela 1.

Tabela 1 - Notas na prova inicial - GT e GC - $1^{\circ}$ Bimestre

\begin{tabular}{ccccccccc}
\hline Grupo & N & Média & $\begin{array}{c}\text { Desvio } \\
\text { Padrão }\end{array}$ & \multicolumn{2}{c}{$\begin{array}{c}\text { 95\% Intervalo de } \\
\text { confiança }\end{array}$} & Min & Max & Moda \\
\hline GT & 34 & 3,0 & 2,7 & 2,0 & 3,9 & 0,0 & 8,0 & 0,0 \\
GC & 32 & 4,1 & 2,7 & 3,1 & 5,1 & 0,0 & 10,0 & 5,0 \\
\hline
\end{tabular}

$\operatorname{Pr}(|\mathbf{T}|>|\mathbf{t}|)=0,0979$

Fonte: Elaborada pelos autores.

O grupo de controle obteve média de 4,1 e o grupo de tratamento, média igual a 3,0. Desta forma, rejeita-se a hipótese de igualdade entre as médias dos dois grupos, com intervalo de confiança de $95 \%$. Para obter-se esse resultado foi utilizado um teste $t$ de igualdade de médias, bicaudal por meio do software Stata. O teste de homogeneidade das variâncias, realizado no mesmo programa, indicou a não rejeição da hipótese nula de igualdade das variâncias, sendo a estatística do teste igual a 0,8938. Este não foi o resultado esperado, dado que os grupos foram divididos aleatoriamente, procurando atender aos aspectos relacionados à validade do experimento. Dado este resultado inicial, foi necessário procurar entender os motivos que levaram a esta diferença. Na Tabela 2 encontra-se uma possível explicação. Os estudantes responderam questões sobre estar ou não e possuir curso técnico. Desta forma, devese observar que essas características observáveis (formação anterior e inserção no mercado de trabalho) acabam gerando quatro possíveis situações. Ou seja, existem estudantes que trabalham e têm curso técnico; os que trabalham e não têm curso técnico; os que não trabalham e possuem curso técnico; e os que não trabalham e não possuem curso técnico.

Em cada situação, mesmo com a randomização na composição dos grupos, há uma quantidade diferente de estudantes por grupo: a frequência de estudantes que trabalham e têm curso técnico é de cinco no GC e nove no GT; os que trabalham e não têm curso técnico são 17 no GC e nove no GT; os que não trabalham e possuem curso técnico são quatro no GC e dois no GT; e a frequência dos que não trabalham e não possuem curso técnico é de seis no GC e 14 no GT. Desta forma, é provável que o número relativamente reduzido de estudantes no experimento (66) pode estar associado às diferenças encontradas nas características dos estudantes do GC e do GT, mesmo com a aleatorização descrita anteriormente.

Observa-se que o GC possui apenas 18,7\% de estudantes que não trabalham e não possuem curso técnico, enquanto no GT esse percentual é de $41,1 \%$. Considerando que a disciplina é do 1o semestre do curso e trata de noções básicas de Contabilidade, pode-se inferir que o estudante que trabalha ou que possui curso técnico já teve algum contato prático com a Contabilidade, de forma distinta do estudante que não trabalha ou não tem curso técnico. Neste aspecto, ressalta-se que 53,2\% do GC trabalha e não tem curso técnico, enquanto $26,5 \%$ do GT está nesta mesma condição.

Mesmo com os cuidados com a aleatorização, há diferenças entre os grupos, particularmente, no que se refere às características de formação anterior e inserção prévia no mercado de trabalho. Nesse sentido, nota-se que, além dessas características observáveis (formação anterior e inserção no mercado de trabalho) serem diferentes entre os componentes dos grupos, o desempenho médio dos estudantes na prova inicial também foi diferente. Esta é uma evidência, ainda que não conclusiva, de que pode haver algum efeito de interação entre as 
características observáveis e a intervenção feita no experimento, o que leva a resultados distintos entre os grupos. Conforme McKechnie, Dunleavy e Hobbs (2005), a experiência profissional pode ter impacto maior ou menor no desempenho acadêmico dos estudantes, em função de certas características de alguns cursos como Engenharia, Administração e Contabilidade, em que a vivência do mercado de trabalho pode ser entendida como um atributo complementar aos conhecimentos obtidos na graduação, com efeitos positivos sobre o desempenho acadêmico. O resultado verificado na prova inicial está alinhado com Byrne e Flood (2009), que afirmam que o conhecimento prévio de contabilidade está positivamente associado com o desempenho geral dos estudantes no primeiro ano do curso de graduação em Contabilidade. Também Miranda et al. (2013) apontam que o conhecimento prévio tem impacto positivo no desempenho.

Tabela 2 - Notas médias por formação anterior e inserção no mercado de trabalho

\begin{tabular}{|c|c|c|c|c|c|c|}
\hline & \multicolumn{3}{|c|}{ GC } & \multicolumn{3}{|c|}{ GT } \\
\hline & Freq. & $\%$ & $\begin{array}{c}\text { Nota } \\
\text { média }\end{array}$ & Freq. & $\%$ & $\begin{array}{l}\text { Nota } \\
\text { média }\end{array}$ \\
\hline Trabalham e têm curso técnico & 5 & 15,60 & 5,6 & 9 & 26,50 & 4,3 \\
\hline Trabalham e não têm curso técnico & 17 & 53,20 & 4,2 & 9 & 26,50 & 2,9 \\
\hline Não trabalham e possuem curso técnico & 4 & 12,50 & 4,3 & 2 & 5,90 & 7,5 \\
\hline Não trabalham e não possuem curso técnico & 6 & 18,70 & 2,5 & 14 & 41,10 & 1,5 \\
\hline Total de estudantes & 32 & 100,00 & 4,1 & 34 & 100,00 & $\mathbf{3 , 0}$ \\
\hline
\end{tabular}

Fonte: Elaborada pelos autores.

As características observáveis que mais diferenciam os grupos concentram-se na situação profissional (DAVIES; RUTHERFORD, 2012). Ou seja, trabalhar ou não trabalhar e possuir ou não curso técnico em Contabilidade. Os estudantes que trabalham tiveram, em média, desempenho superior aos estudantes que não trabalham. Com o GC tinha maior número de estudantes nesta condição frente ao GT ( 22 x 18), este fato, em consonância com a literatura, deve ter levado à diferença no desempenho na prova inicial. Além disso, a distribuição inicial colocou 14 estudantes que não trabalham e não possuem curso técnico no GT e seis estudantes nesta condição no GC, fazendo com que essa característica observável tivesse maior interferência na diferença das médias iniciais dos dois grupos.

Essa desigualdade de médias tem efeitos sobre o desenvolvimento do trabalho, pois o esperado era que o teste de igualdade entre as médias indicasse a hipótese de que as notas médias da prova inicial seriam iguais. Assim, diferenças verificadas na prova final poderiam ser atribuídas ao efeito do tratamento, ou seja, à adoção de tecnologias (GALL et al., 2002). No entanto, a rejeição da hipótese de igualdade entre as notas médias iniciais exige maior cuidado na interpretação do efeito do tratamento, para verificar se a variação verificada é decorrente unicamente da intervenção efetuada, o uso da tecnologia.

Concluindo esta seção, verifica-se que o grupo de controle tem proporção um pouco maior de estudantes com idade até 25 anos $(56,3 \%)$, enquanto o grupo de tratamento possui $50 \%$ de estudantes nesta faixa etária. A idade média do GC é um pouco menor ( 25 anos) em relação à média de idade do GT (26). O teste de médias populacionais rejeita a hipótese de que as idades médias dos grupos sejam iguais. Na sequência, a Tabela 3 mostra a idade aproximada em que os estudantes tiveram o primeiro contato com o computador e com um dispositivo móvel. Verifica-se que, em função de os grupos possuírem, em sua maioria, a faixa etária de até 25 anos, o primeiro contato com o computador ocorreu, em média, com 12,4 anos de idade no GT e com 13 anos no GC; e com um dispositivo móvel ocorreu, em média, com 13,9 anos no GT e 14,1 anos no GC. Pelo menos oito estudantes de cada grupo apontaram a idade inferior 
a 10 anos como o primeiro contato com a tecnologia, apresentando características de nativos digitais. No GT, 23,5\% dos estudantes tiveram contato com o computador com idade inferior a 10 anos; no grupo de controle esse percentual foi de 18,8\%. No grupo de controle, $25 \%$ dos estudantes tiveram contato com um dispositivo móvel com idade inferior a 10 anos.

Tabela 3 - Primeiro contato com a tecnologia por grupo etário

\begin{tabular}{|c|c|c|c|c|c|c|c|c|}
\hline \multirow{3}{*}{$\begin{array}{l}\text { Grupo etário } \\
\text { Inferior a } 10 \text { anos }\end{array}$} & \multicolumn{4}{|c|}{ Computador } & \multicolumn{4}{|c|}{ Dispositivo móvel } \\
\hline & \multicolumn{2}{|r|}{ GT } & \multicolumn{2}{|r|}{ GC } & \multicolumn{2}{|r|}{ GT } & \multicolumn{2}{|r|}{ GC } \\
\hline & 8 & $23,5 \%$ & 6 & $18,8 \%$ & 5 & $14,7 \%$ & 8 & $25,0 \%$ \\
\hline 10 a 15 anos & 18 & $52,9 \%$ & 20 & $62,5 \%$ & 19 & $55,9 \%$ & 15 & $46,9 \%$ \\
\hline 16 a 20 anos & 7 & $20,6 \%$ & 4 & $12,5 \%$ & 7 & $20,6 \%$ & 6 & $18,8 \%$ \\
\hline 21 a 25 anos & 0 & $0,0 \%$ & 1 & $3,1 \%$ & 2 & $5,9 \%$ & 1 & $3,1 \%$ \\
\hline 26 a 30 anos & 1 & $2,9 \%$ & 1 & $3,1 \%$ & 1 & $2,9 \%$ & 2 & $6,2 \%$ \\
\hline Total & 34 & $100,0 \%$ & 32 & $100,0 \%$ & 34 & $100,0 \%$ & 32 & $100,0 \%$ \\
\hline $\begin{array}{l}\text { Idade média do } 1^{\circ} \text { contato } \\
\text { (anos) }\end{array}$ & & 12,4 & & 13,0 & & 13,9 & & 14,1 \\
\hline
\end{tabular}

Fonte: Elaborada pelos autores.

\subsection{Experimento $-1^{\circ}$ bimestre}

No início do experimento foi estabelecido um cronograma que previa a realização de dois chats e um fórum de discussão para o grupo de tratamento em cada bimestre. No dia 25/03/2015 ocorreu a primeira interação com uso de tecnologia - aula chat. Foi realizada uma atividade prática relacionada à estrutura conceitual básica. Em cada transação, a professora apresentava o enunciado do fato ocorrido e os estudantes informavam o efeito que a transação provocava. A partir da resposta dos estudantes, a professora confirmava o resultado ou apontava erros. No chat os estudantes leem todas as informações que são postadas (suas e de seus colegas), e a qualquer momento podem e revisar o que haviam postado. $\mathrm{O}$ chat começou aproximadamente às 19 horas e foi encerrado às 22 horas. A atividade foi realizada sem imprevistos. Dos 34 estudantes do grupo de tratamento apenas quatro não realizaram esta atividade. Dos 30 estudantes que participaram do chat, 28 fizeram ao menos uma interação durante a aula. No total ocorreram 1.570 intervenções, sendo 522 da professora e as demais dos estudantes. A média de intervenções por estudante foi de 35 , sendo que o máximo de intervenções por um estudante foram 115 e o mínimo foi uma intervenção. As intervenções representam todas as postagens feitas durante o chat, seja uma pergunta, um comentário ou qualquer outra ação do professor ou dos estudantes registradas durante o período de realização do chat.

No dia 02/04/2015 teve início o fórum de discussão. Este foi conduzido a partir de um caso prático sobre "dimensão econômica versus financeira", ou seja, relação entre resultado econômico (lucro) e situação financeira (caixa). A professora apresentou um caso e solicitou aos estudantes que argumentassem se concordavam ou não com a situação apresentada. Este procedimento está de acordo com Strang (2011), que aponta que a abordagem tradicional para criar interação em fóruns de discussão online é usar perguntas que façam os estudantes refletir criticamente sobre as diversas respostas, para desenvolver uma comunidade de colaboração entre os participantes.

O fórum foi realizado no sistema Moodle, ficando aberto até o dia 10 de abril, às 23 horas. Participaram desta atividade 17 estudantes. Apesar de a maioria das intervenções consistir de respostas pontuais ao questionamento da professora, sem haver discussão entre os estudantes, mais de 50\% do grupo participou. No caso do presente estudo, o fórum constituiu- 
se de um conjunto de relatos a respeito do tema proposto, em que mesmo os estudantes que não emitiram sua opinião tiveram a oportunidade de interpretar a opinião dos colegas, fazendo com que a atividade fosse concluída com participação efetiva dos estudantes.

A segunda interação com uso de chat aconteceu no dia 15/04/2015. Reproduzindo o mesmo modelo adotado no primeiro chat, a professora revisou os principais conceitos relacionados ao tema escrituração de diário e razão, deixando os estudantes emitirem opiniões sobre essas definições. Na sequência, tratou sobre o encerramento das contas de resultado e sobre o balancete de verificação, sempre deixando espaço para os alunos fazerem questionamentos. Essa etapa da aula durou até as $19 \mathrm{~h} 31 \mathrm{~min}$, momento em que a professora começou a discutir o exercício prático. Em caso de erros, a professora fazia as devidas correções. A atividade foi realizada sem imprevistos. Houve participação de 28 estudantes, sendo que 25 fizeram pelo menos uma interação durante a aula. No total ocorreram 970 intervenções, sendo que 443 foram da professora e as demais dos estudantes. A média de intervenções por estudante foi 19, sendo que o máximo de intervenções por um estudante foram 98 e o mínimo foi uma intervenção. Nos demais dias ocorreram aulas presenciais no grupo de tratamento. No grupo de controle, todas as aulas foram presenciais.

Tabela 4 - Desempenho dos estudantes do grupo de tratamento (GT) nas provas - Primeiro bimestre

\begin{tabular}{|c|c|c|c|}
\hline Grupo de Tratamento & Prova inicial & Prova final & Variação \\
\hline Estudante Tratamento 1 & 3,0 & 9,5 & 6,5 \\
\hline Estudante Tratamento 2 & 3,0 & 6,0 & 3,0 \\
\hline Estudante Tratamento 3 & 0,0 & 8,5 & 8,5 \\
\hline Estudante Tratamento 4 & 4,0 & 6,5 & 2,5 \\
\hline Estudante Tratamento 7 & 3,0 & 7,5 & 4,5 \\
\hline Estudante Tratamento 8 & 0,0 & 7,5 & 7,5 \\
\hline Estudante Tratamento 9 & 3,0 & 2,2 & $-0,8$ \\
\hline Estudante Tratamento 10 & 2,0 & 3,9 & 1,9 \\
\hline Estudante Tratamento 11 & 0,0 & 6,5 & 6,5 \\
\hline Estudante Tratamento 12 & 0,0 & 1,0 & 1,0 \\
\hline Estudante Tratamento 13 & 8,0 & 9,3 & 1,3 \\
\hline Estudante Tratamento 14 & 5,0 & 9,7 & 4,7 \\
\hline Estudante Tratamento 15 & 6,0 & 8,5 & 2,5 \\
\hline Estudante Tratamento 16 & 1,0 & 9,8 & 8,8 \\
\hline Estudante Tratamento 17 & 0,0 & 8,9 & 8,9 \\
\hline Estudante Tratamento 19 & 5,0 & 8,8 & 3,8 \\
\hline Estudante Tratamento 20 & 8,0 & 8,1 & 0,1 \\
\hline Estudante Tratamento 21 & 0,0 & 7,6 & 7,6 \\
\hline Estudante Tratamento 22 & 0,0 & 9,4 & 9,4 \\
\hline Estudante Tratamento 23 & 8,0 & 9,5 & 1,5 \\
\hline Estudante Tratamento 24 & 7,0 & 6,8 & $-0,2$ \\
\hline Estudante Tratamento 25 & 3,0 & 7,0 & 4,0 \\
\hline Estudante Tratamento 26 & 1,0 & 6,3 & 5,3 \\
\hline Estudante Tratamento 27 & 1,0 & 4,3 & 3,3 \\
\hline Estudante Tratamento 28 & 0,0 & 7,0 & 7,0 \\
\hline Estudante Tratamento 29 & 1,0 & 3,9 & 2,9 \\
\hline Estudante Tratamento 30 & 7,0 & 9,3 & 2,3 \\
\hline Estudante Tratamento 31 & 1,0 & 6,0 & 5,0 \\
\hline Estudante Tratamento 32 & 2,0 & 7,6 & 5,6 \\
\hline Estudante Tratamento 33 & 0,0 & 0,6 & 0,6 \\
\hline Estudante Tratamento 34 & 4,0 & 1,3 & $-2,7$ \\
\hline Média & 2,77 & 6,74 & 3,97 \\
\hline
\end{tabular}

Fonte: Elaborada pelos autores.

No final do bimestre foi aplicada uma prova para avaliar o desempenho dos estudantes dos dois grupos. Essa prova começou às 19:15h e terminou às $22 \mathrm{~h}$. A Tabela 4 apresenta as 
notas da primeira e da segunda prova do grupo de tratamento, onde a primeira é a nota inicial do bimestre e a segunda é a prova final do bimestre. No início do bimestre havia 34 estudantes no GT. Com a desistência de três alunos, restaram 31. A média passou de 2,77 para 6,74, o que significa um aumento de 3,97 pontos, ou que significa $143 \%$ ao longo do bimestre.

Tabela 5 - Desempenho dos estudantes do grupo de controle (GC) nas provas - Primeiro bimestre

\begin{tabular}{|c|c|c|c|}
\hline Estudante & Nota inicial & Nota final & Variação \\
\hline Estudante controle 1 & 6,0 & 7,7 & 1,7 \\
\hline Estudante controle 2 & 7,0 & 7,0 & 0,0 \\
\hline Estudante controle 3 & 10,0 & 7,7 & $-2,3$ \\
\hline Estudante controle 4 & 0,0 & 6,7 & 6,7 \\
\hline Estudante controle 5 & 5,0 & 7,8 & 2,8 \\
\hline Estudante controle 6 & 0,0 & 5,7 & 5,7 \\
\hline Estudante controle 7 & 1,0 & 2,0 & 1,0 \\
\hline Estudante controle 8 & 5,0 & 7,6 & 2,6 \\
\hline Estudante controle 9 & 6,0 & 2,6 & $-3,4$ \\
\hline Estudante controle 10 & 2,0 & 3,4 & 1,4 \\
\hline Estudante controle 11 & 2,0 & 6,4 & 4,4 \\
\hline Estudante controle 12 & 3,0 & 9,6 & 6,6 \\
\hline Estudante controle 13 & 5,0 & 8,0 & 3,0 \\
\hline Estudante controle 15 & 5,0 & 8,7 & 3,7 \\
\hline Estudante controle 16 & 4,0 & 9,3 & 5,3 \\
\hline Estudante controle 18 & 5,0 & 8,7 & 3,7 \\
\hline Estudante controle 19 & 5,0 & 6,8 & 1,8 \\
\hline Estudante controle 20 & 6,0 & 9,3 & 3,3 \\
\hline Estudante controle 21 & 8,0 & 7,6 & $-0,4$ \\
\hline Estudante controle 22 & 2,0 & 7,4 & 5,4 \\
\hline Estudante controle 23 & 6,0 & 8,6 & 2,6 \\
\hline Estudante controle 24 & 0,0 & 3,3 & 3,3 \\
\hline Estudante controle 25 & 2,0 & 4,0 & 2,0 \\
\hline Estudante controle 26 & 1,0 & 5,9 & 4,9 \\
\hline Estudante controle 27 & 4,0 & 2,4 & $-1,6$ \\
\hline Estudante controle 28 & 6,0 & 9,8 & 3,8 \\
\hline Estudante controle 29 & 1,0 & 2,8 & 1,8 \\
\hline Estudante controle 30 & 7,0 & 8,6 & 1,6 \\
\hline Estudante controle 31 & 3,0 & 4,2 & 1,2 \\
\hline Estudante controle 32 & 0,0 & 8,0 & 8,0 \\
\hline Média & 3,90 & 6,59 & 2,69 \\
\hline
\end{tabular}

Fonte: Elaborada pelos autores.

A Tabela 5 apresenta os resultados do GC nas provas. A nota média cresceu 2,69 pontos, passando 3,90 para 6,59, o que representa um incremento de $169 \%$. Este crescimento, inferior ao verificado para o GT, é um resultado similar ao verificado na literatura. Conforme Jena (2011), o ensino e a aprendizagem por meio de tecnologias da educação podem ser adotados para aumentar a capacidade de aprendizagem refletindo no desempenho. No estudo de Tas (2011), cujo objetivo foi investigar a eficácia no desempenho dos estudantes a partir de um novo material desenvolvido na web, o desempenho dos estudantes melhorou nos dois grupos, sendo que o grupo de tratamento teve um crescimento de $53 \%$ nas notas, e o grupo de controle, de $31 \%$.

Na sequência, foi realizada uma tabulação cruzada entre as notas médias e a idade dos estudantes, para verificar se havia associação entre ambas. A Tabela 6 mostra que o maior crescimento médio no desempenho $(5,14$ pontos) foi verificado para os estudantes do GT com menos de 20 anos. Adicionalmente, a média final deste grupo no GT foi 17,2\% superior à média final do GC. Foi rejeitada a hipótese de igualdade entre as médias dos dois grupos. Para os estudantes com idade de entre 20 e 25 anos, A média inicial do GT era 0,05\% maior do que a 
do GC, e a média final o GT passou a ser 13,2\% maior que o GC. Também aqui o teste de médias indicou rejeição da hipótese de igualdade entre os valores médios.

Tabela 6 - Desempenho dos estudantes do grupo de controle (GC), por grupo etário - Primeiro bimestre

\begin{tabular}{|c|c|c|c|c|c|c|}
\hline \multirow[b]{2}{*}{ Grupo etário } & \multicolumn{3}{|c|}{ GT } & \multicolumn{3}{|c|}{ GC } \\
\hline & $\begin{array}{c}\text { Nota } \\
\text { inicial }\end{array}$ & $\begin{array}{l}\text { Nota } \\
\text { final }\end{array}$ & Variação & $\begin{array}{c}\text { Nota } \\
\text { inicial }\end{array}$ & $\begin{array}{l}\text { Nota } \\
\text { final }\end{array}$ & Variação \\
\hline menos de 20 anos & 1,73 & 6,87 & 5,14 & 2,63 & 5,86 & 3,23 \\
\hline entre 20 e 25 anos & 4,40 & 7,98 & 3,58 & 4,38 & 7,05 & 2,67 \\
\hline entre 26 e 30 anos & 3,50 & 6,23 & 2,73 & 4,44 & 6,44 & 2,00 \\
\hline mais de 30 anos & 2,43 & 6,21 & 3,78 & 4,20 & 7,26 & 3,06 \\
\hline Média geral & 2,77 & 6,74 & 3,97 & 3,90 & 6,59 & 2,69 \\
\hline
\end{tabular}

Fonte: Elaborada pelos autores.

Também na faixa etária entre 26 e 30 anos rejeitou-se a hipótese de igualdade entre as médias. Por outro lado, a média final dos estudantes com mais de 30 anos do GC foi a maior verificada, além de ser 16,9\% superior à média de notas dos estudantes com mais de 30 anos do GT. O teste de médias também indicou a rejeição da hipótese de igualdade entre ambas. Esses resultados podem estar relacionados ao fato de que os estudantes com menos de 25 anos têm maior habilidade com o uso da tecnologia, pois começaram a ter contato com a tecnologia mais jovens. Esse resultado vai ao encontro do exposto por Carneiro et al. (2009), que afirmam que o desenvolvimento acelerado da sociedade da informação traz desafios importantes para o ensino e aprendizagem. Neste contexto, uma nova geração de estudantes, que não passaram por um período de transição para as novas tecnologias (visto que são contemporâneos), acabam adquirindo o conhecimento de forma diferente da que ocorreu com as gerações anteriores, por meio do uso da tecnologia.

\subsection{Experimento $-2^{\circ}$ bimestre}

No segundo bimestre, os grupos foram invertidos, de forma que o GT do $1^{\circ}$ bimestre passou a ser o GC e vice-versa. Essa inversão ocorreu em função das principais ameaças ligadas às variáveis externas que podem comprometer a validade interna, exposta por Gall et al. (2002) em que se destaca a "equalização compensatória no tratamento" e a "desmoralização ressentida do grupo de controle", pois essas variáveis estão relacionadas à percepção de desvantagens para os estudantes que estão no grupo de controle. Feita esta alteração, no dia 13 de maio de 2015, o pesquisador participou da parte inicial da aula com o GC, para informar que a partir daquele momento a turma não teria mais as interações com tecnologia (chat e fórum). No dia seguinte, o pesquisador teve contato com o GT, informando que no segundo bimestre passariam a ter algumas interações com o uso de tecnologia (chat e fórum), conforme o cronograma estabelecido pela professora. Nas duas turmas não houve nenhuma manifestação de contrariedade ou dificuldade em relação ao esquema proposto. A partir de então, o experimento repetiu as etapas realizadas no primeiro bimestre. Nestas aulas iniciais, também foi aplicada uma prova com os conteúdos que seriam ministrados durante o $2^{\circ}$ bimestre. Essa prova teve a finalidade de quantificar o conhecimento prévio sobre o assunto a ser ministrado. A prova teve duração aproximada de 30 minutos, em cada turma, e foi elaborada pela professora, na forma de um teste, com nove questões de múltipla escolha e uma questão aberta. Neste bimestre, o número de alunos nas turmas foi menor em função das desistências ocorridas no $1^{\circ}$ bimestre, ficando 30 alunos em cada grupo. Os resultados são apresentados na Tabela 7. 
Tabela 7 - Notas na prova inicial - GT e GC $-2^{\circ}$ Bimestre

\begin{tabular}{ccccccccc}
\hline Grupo & N & Média & $\begin{array}{c}\text { Desvio } \\
\text { Padrão }\end{array}$ & $\begin{array}{c}\text { 95\% Intervalo de } \\
\text { confiança }\end{array}$ & Min & Max & Moda \\
\hline GT & 30 & 1,2 & 1,2 & 0,7 & 1,6 & 0,0 & 4,0 & 0,0 \\
GC & 30 & 1,3 & 1,5 & 0,8 & 1,9 & 0,0 & 5,0 & 1,0 \\
\hline
\end{tabular}

$\operatorname{Pr}(|\mathbf{T}|>|\mathbf{t}|)=0,6027$

Fonte: Elaborada pelos autores.

$\mathrm{Na}$ Tabela 7 , percebe-se que as médias do $2^{\circ}$ bimestre foram menores que as do $1^{\circ}$ bimestre. O GT do $2^{\circ}$ bimestre teve média de 1,3 . No $1^{\circ}$ bimestre a média havia sido 2,97 . Para o $\mathrm{GC}$ do $2^{\circ}$ bimestre as médias foram, respectivamente, 1,2 e 4,09. No segundo bimestre, o conteúdo desenvolvido na disciplina tratou dos princípios de Contabilidade e do controle de estoque. Esses conteúdos exigem mais conhecimento prévio do que os conteúdos do $1^{\circ}$ bimestre, que abordaram noções básicas de Contabilidade. Esta diferença entre os conteúdos pode ter gerado a piora verificada no desempenho médio. O grupo de controle atingiu média de 1,3 e o grupo de tratamento média de 1,2, no segundo bimestre. Entretanto, apesar de valores tão próximos, rejeita-se a hipótese de igualdade entre as médias dos dois grupos com intervalo de confiança de $95 \%$. Para obter-se esse resultado foi utilizado um teste t de igualdade de médias, bicaudal por meio do software Stata. O teste de homogeneidade das variâncias indicou não rejeição da hipótese de igualdade das variâncias, com resultado do teste de 0,2751.

Tabela 8 - Desempenho dos estudantes do grupo de tratamento (GT) nas provas - Segundo bimestre

\begin{tabular}{l|c|c|c}
\hline Estudante & Nota inicial & Nota final & Variação \\
\hline Estudante Tratamento 1 & 1,0 & 2,2 & 1,2 \\
\hline Estudante Tratamento 2 & 0,0 & 6,2 & 6,2 \\
\hline Estudante Tratamento 4 & 0,0 & 6,5 & 4,9 \\
\hline Estudante Tratamento 5 & 2,0 & 6,9 & 6,2 \\
\hline Estudante Tratamento 6 & 0,0 & 6,2 & 5,0 \\
\hline Estudante Tratamento 7 & 0,0 & 5,0 & 5,4 \\
\hline Estudante Tratamento 8 & 1,0 & 6,4 & 4,1 \\
\hline Estudante Tratamento 11 & 3,0 & 7,1 & 9,0 \\
\hline Estudante Tratamento 12 & 1,0 & 10,0 & 6,5 \\
\hline Estudante Tratamento 13 & 3,0 & 9,5 & 4,0 \\
\hline Estudante Tratamento 15 & 1,0 & 5,0 & 8,3 \\
\hline Estudante Tratamento 16 & 0,0 & 8,3 & 7,2 \\
\hline Estudante Tratamento 17 & 1,0 & 8,2 & 6,1 \\
\hline Estudante Tratamento 19 & 0,0 & 6,1 & 5,9 \\
\hline Estudante Tratamento 20 & 2,0 & 7,9 & 4,8 \\
\hline Estudante Tratamento 21 & 1,0 & 5,8 & 7,6 \\
\hline Estudante Tratamento 22 & 0,0 & 7,6 & 7,5 \\
\hline Estudante Tratamento 23 & 0,0 & 7,5 & 0,6 \\
\hline Estudante Tratamento 24 & 0,0 & 0,6 & 0,4 \\
\hline Estudante Tratamento 25 & 0,0 & 0,4 & 1,7 \\
\hline Estudante Tratamento 26 & 4,7 & 0,5 \\
\hline Estudante Tratamento 27 & 3,0 & 0,5 & 7,8 \\
\hline Estudante Tratamento 28 & 0,0 & 8,8 & 6,8 \\
\hline Estudante Tratamento 29 & 1,0 & 7,8 & $\mathbf{5 , 2 5}$ \\
\hline Estudante Tratamento 30 & 1,0 & 9,0 & $\mathbf{6 , 1 7}$ \\
\hline Média & 2,0 & & \\
\hline Eonte: Ela2 & & \\
\hline
\end{tabular}

Fonte: Elaborada pelos autores.

No transcorrer do $2^{\circ}$ bimestre, foram realizados dois chats e um fórum de discussão com o grupo de tratamento. O primeiro chat teve a participação de 27 estudantes, do total de 30 que continuaram frequentando a disciplina. Ao final ocorreram 1.241 intervenções, sendo que 543 
foram da professora e as demais dos estudantes. A média de intervenções por estudante foi 26 , sendo o máximo 161 e o mínimo uma intervenção. O fórum iniciado em 23 de maio ficou aberto até 23:55h do dia $1^{\circ}$ de junho, e houve uma participação menos efetiva dos estudantes quanto ao número de intervenções. Ao final, seis estudantes participaram da atividade, gerando oito intervenções. Os demais estudantes acessaram o fórum, mas não se manifestaram. No último chat ocorreram 806 intervenções, sendo que 447 foram da professora e as demais dos estudantes. A média de intervenções por estudante foi 19 , sendo que o máximo foi de 87 e o mínimo foi uma intervenção.

A Tabela 8 mostra o desempenho dos estudantes do grupo de tratamento na prova inicial e na prova final. A prova final foi aplicada no último dia de aula, envolvendo todo o conteúdo ministrado durante o bimestre. O GT possuía 30 estudantes e no transcorrer do bimestre ocorreram cinco desistências.

A Tabela 9 apresenta o desempenho do GC nas duas provas. Esta turma inicialmente possuía 30 estudantes, mas ocorreram seis desistências e restaram 24 alunos. Os resultados da prova final evidenciam um crescimento médio superior entre as notas iniciais e finais, comparativamente ao GT. A variação média no GC foi 5,73 e no GT foi 5,25. A nota média final do GC foi 7,27 e do GT foi 6,17.

Tabela 9 - Desempenho dos estudantes do grupo de controle (GC) nas provas - Segundo bimestre

\begin{tabular}{l|c|c|c}
\hline \multicolumn{1}{c|}{ Grupo de controle } & Nota inicial & Nota final & Variação \\
\hline Estudante controle 1 & 0,0 & 9,8 & 9,8 \\
\hline Estudante controle 2 & 0,0 & 7,5 & 7,5 \\
\hline Estudante controle 3 & 1,0 & 8,7 & 1,7 \\
\hline Estudante controle 4 & 1,0 & 2,7 & 4,4 \\
\hline Estudante controle 5 & 0,0 & 4,4 & 3,7 \\
\hline Estudante controle 6 & 1,5 & 5,2 & 3,0 \\
\hline Estudante controle 8 & 1,0 & 4,0 & $-2,4$ \\
\hline Estudante controle 9 & 4,0 & 1,6 & 7,8 \\
\hline Estudante controle 11 & 2,0 & 9,8 & 6,8 \\
\hline Estudante controle 12 & 3,0 & 9,8 & 7,5 \\
\hline Estudante controle 13 & 5,0 & 9,5 & 8,3 \\
\hline Estudante controle 14 & 2,0 & 9,6 & 6,7 \\
\hline Estudante controle 15 & 1,0 & 9,3 & 8,4 \\
\hline Estudante controle 16 & 1,0 & 7,7 & 9,1 \\
\hline Estudante controle 17 & 0,0 & 8,4 & 6,0 \\
\hline Estudante controle 19 & 0,0 & 9,1 & 6,5 \\
\hline Estudante controle 20 & 4,0 & 10,0 & 8,0 \\
\hline Estudante controle 21 & 1,5 & 8,0 & 7,2 \\
\hline Estudante controle 22 & 1,0 & 9,0 & 7,6 \\
\hline Estudante controle 23 & 1,0 & 8,2 & 3,6 \\
\hline Estudante controle 25 & 0,0 & 7,6 & 0,6 \\
\hline Estudante controle 27 & 5,0 & 8,6 & $\mathbf{5 , 7 3}$ \\
\hline Estudante controle 28 & 2,0 & 2,6 & 3,5 \\
\hline Estudante controle 29 & 0,0 & $\mathbf{7 , 2 7}$ & \\
\hline Média & $\mathbf{1 , 5 4}$ & & \\
\hline Fonte: Elaborada pelos aut & & \\
\hline
\end{tabular}

Fonte: Elaborada pelos autores.

Com base nos dados da Tabela 10 é possível constatar que os estudantes do GT com idade até 25 anos tiveram um crescimento mais significativo em seu desempenho, em comparação aos estudantes desta idade do GC. Os estudantes do GT com idade entre 20 e 25 anos tiveram um crescimento em seu desempenho de 6,24 pontos em relação à nota da prova inicial, enquanto o mesmo grupo do GC teve incremento de 5,16 pontos. O teste de médias indicou a rejeição da hipótese de igualdade entre o desempenho médio final dos estudantes entre 20 e 25 anos dos dois grupos. 
Tabela 10 - Desempenho Médio dos Estudantes por Idade - $2^{\circ}$ Bimestre

\begin{tabular}{|c|c|c|c|c|c|c|}
\hline \multirow[b]{2}{*}{ Idade } & \multicolumn{3}{|c|}{ Grupo de Tratamento } & \multicolumn{3}{|c|}{ Grupo de Controle } \\
\hline & $\begin{array}{l}\text { Nota } \\
\text { inicial }\end{array}$ & Nota final & $\begin{array}{l}\text { Variação } \\
\text { absoluta }\end{array}$ & $\begin{array}{c}\text { Nota } \\
\text { inicial }\end{array}$ & Nota final & $\begin{array}{l}\text { Variação } \\
\text { absoluta }\end{array}$ \\
\hline menos de 20 anos & 1,25 & 5,61 & 4,36 & 1,94 & 6,29 & 4,35 \\
\hline entre 20 e 25 anos & 0,43 & 6,67 & 6,24 & 1,40 & 6,56 & 5,16 \\
\hline entre 26 e 30 anos & 0,50 & 5,30 & 4,80 & 1,25 & 8,10 & 6,85 \\
\hline mais de 30 anos & 1,75 & 7,70 & 5,95 & 1,40 & 8,58 & 7,18 \\
\hline Média geral & 0,92 & 6,17 & 5,25 & 1,54 & 7,27 & 5,73 \\
\hline
\end{tabular}

Fonte: Elaborada pelos autores.

Os estudantes com mais de 30 anos do GC tiveram a média final mais elevada, além desta ser $11 \%$ superior ao grupo equivalente do GT. Rejeitou-se a hipótese de igualdade entre as médias finais destes dois grupos. Esses resultados são similares àqueles verificados no $1^{\circ}$ bimestre, quando a variação das notas dos estudantes mais jovens do GT foi superior ao do mesmo grupo do GC. Já para os estudantes mais velhos o resultado é invertido. Ou seja, a variação maior ocorreu no GC, indicando que a idade é uma variável que interfere no desempenho, quando é utilizada a tecnologia (MAGALHÃES; ANDRADE, 2006).

\subsection{Comparação entre os resultados dos bimestres}

A Tabela 11 sumariza os resultados das avaliações. Nas linhas estão apresentadas as médias do GT e do GC, bem como a diferença entre os grupos em cada bimestre. Nas colunas, além das notas inicial e final são reportadas a diferença entre ambos, em termos absolutos e em termos percentuais. De acordo com o apontado previamente nas Tabelas 5 e 10, um teste $t$ de médias rejeita a hipótese de igualdade de notas entre os grupos, em ambos os bimestres. A explicação para este fato, não-previsto, deve estar, conforme análise desenvolvida na seção 4.1 em diferenças observáveis entre os dois grupos; neste caso a inserção no mercado de trabalho e ter cursado o curso técnico de contabilidade.

A turma que foi o GT no $1^{\circ}$ bimestre e o GC no $2^{\circ}$ teve desempenho superior à outra turma, em três das quatro notas reportadas. A exceção foi a nota final no $1^{\circ}$ bimestre, em que a nota do GC $(7,27)$ foi superior à do GT $(6,74)$. Os dois grupos tiveram aumentos em suas notas, da avaliação inicial para a final, ainda que com magnitude diferenciada. Mas deve-se atentar para a diferença percentual, cujos valores podem ser vistos na última coluna à direita da Tabela 11. No primeiro bimestre, o GT teve um incremento percentual de $143 \%$ na nota, comparativamente aos $69 \%$ do GC. No segundo bimestre, quando houve a inversão da turmas, o GT novamente teve maior ganho percentual (571\% frente à $372 \%)$. Como o GT é que foi exposto à tecnologia, esses resultados são uma evidência de que o uso de tecnologia beneficiou as turmas no momento em que eram GT, aumentando o desempenho dos alunos. Assim, conforme Luckesi (2005), a avaliação dos resultados contribui para apreciar a eficácia dos recursos tecnológicos utilizados, identificando os mecanismos que, de alguma forma, contribuem para esse processo. O impacto positivo da tecnologia sobre o desempenho acadêmico não é totalmente consensual na literatura. Por exemplo, Morris, Burnett, Skousen, \& Akaaboune (2015) encontraram evidência similar, mas Chan, Song, Rivera, \& Trongmateerut (2016) não reportam evidência significativa da associação entre tecnologia e desempenho acadêmico.

Cabem mencionar ainda que a comparação das notas entre os bimestres tem uma limitação: a possível diferença entre o grau de dificuldade dos conteúdos de um bimestre para outro. No primeiro bimestre, os conteúdos ministrados trataram de noções iniciais de Contabilidade. Considerando que parte das turmas já possuía curso técnico ou experiência 
profissional, esses conteúdos seriam de fácil entendimento para esses estudantes. Essa situação pode ter influenciado as notas iniciais médias dos grupos, quando houve a rejeição da hipótese de igualdade entre as médias iniciais. A prova inicial abordou temas básicos. Assim, qualquer contato anterior com contabilidade (profissional ou acadêmico) deixava o estudante que possuía experiência anterior sobre o tema em condições de obter melhor desempenho. Mesmo com a randomização, uma quantidade maior de estudantes que não trabalham e não têm curso técnico ficaram no GT; em consequência, este grupo teve, em média, um desempenho pior. No segundo bimestre, os conteúdos foram um pouco mais avançados. No entanto, com a base de conhecimento obtida no primeiro bimestre, era de se esperar que os grupos tivessem condições de apresentar desempenho semelhante. Todavia, rejeitou-se a hipótese de igualdade entre a variação das médias das notas dos grupos no segundo bimestre.

Tabela 11 - Notas inicial e final - GT e GC $-1^{\circ} \mathrm{e} 2^{\circ}$ bimestres

\begin{tabular}{ccccc}
\hline $\mathbf{1}^{\mathbf{0}}$ bimestre & Nota inicial & Nota final & Diferença & Diferença $(\boldsymbol{\%})$ \\
\hline GT & 2,77 & 6,74 & 3,97 & $143 \%$ \\
GC & 3,90 & 6,59 & 2,69 & 69 \\
\hline Diferença (GT-GC) & $\mathbf{- 1 , 1 3}$ & $\mathbf{0 , 1 5}$ & $\mathbf{1 , 2 8}$ & $\mathbf{- 1 1 3}$ \\
\hline $\mathbf{2}^{\mathbf{o}}$ bimestre & & & & 571 \\
\hline GT & 0,92 & 6,17 & 5,25 & 372 \\
GC & 1,54 & 7,27 & 5,73 & $\mathbf{7 7}$ \\
\hline
\end{tabular}

Fonte: elaborada pelos autores

Tabela 12 - Desempenho médio por grupo etário nos bimestres

\begin{tabular}{lcccccc}
\hline \multicolumn{1}{c}{ Idade } & $\begin{array}{c}\text { Nota final } \\
\text { GT } \\
\mathbf{1}^{\mathbf{0}} \text { bimestre }\end{array}$ & $\begin{array}{c}\text { Nota final } \\
\text { GC } \\
\mathbf{2}^{\mathbf{o}} \text { bimestre }\end{array}$ & Variação & $\begin{array}{c}\text { Nota final } \\
\text { GT } \\
\mathbf{2}^{\mathbf{0}} \text { bimestre }\end{array}$ & $\begin{array}{c}\text { Nota final } \\
\text { GC } \\
\mathbf{1}^{\mathbf{0}} \text { bimestre }\end{array}$ & Variação \\
\hline menos de 20 anos & 6,87 & 6,29 & $\mathbf{- 0 , 5 8}$ & 5,61 & 5,86 & $\mathbf{0 , 2 5}$ \\
entre 20 e 25 anos & 7,98 & 6,56 & $\mathbf{- 1 , 4 2}$ & 6,67 & 7,05 & $\mathbf{0 , 3 8}$ \\
entre 26 e 30 anos & 6,23 & 8,10 & $\mathbf{1 , 8 7}$ & 5,30 & 6,44 & $\mathbf{1 , 1 4}$ \\
mais de 30 anos & 6,21 & 8,58 & $\mathbf{2 , 3 7}$ & 7,70 & 7,26 & $\mathbf{- 0 , 4 4}$ \\
\hline Média geral & $\mathbf{6 , 7 4}$ & $\mathbf{7 , 2 7}$ & - & $\mathbf{6 , 1 7}$ & $\mathbf{6 , 5 9}$ & - \\
\hline
\end{tabular}

Fonte: elaborada pelos autores

A Tabela 12 sintetiza os achados da relação entre idade uso de recursos tecnológicos. Na turma que foi o GT no $1^{\circ}$ bimestre e o GC no $2^{\circ}$ essa situação é mais evidente, pois os estudantes com idade até 25 anos tiveram desempenho superior quando a turma era o GT e os estudantes acima de 25 anos tiveram melhor desempenho quando a turma era o GC. Na turma que foi o GC no $1^{\circ}$ bimestre e o GT no $2^{\circ}$, as notas médias finais foram menores quando ela era o GT, independentemente da idade, com exceção da faixa entre 20 e 25 anos, onde a média foi maior quando ela era GT.

\section{CONCLUSÕES}

Neste estudo visou-se analisar o impacto do uso da tecnologia sob o desempenho acadêmico. Para tanto, adotou-se como estratégia a realização de um experimento em uma turma da disciplina Contabilidade Introdutória, do curso de Ciências Contábeis presencial de uma Universidade Pública Federal. A composição dos Grupos de Tratamento e de Controle foi feita de forma aleatória. O Grupo de Tratamento do primeiro bimestre tornou-se o Grupo de Controle do segundo bimestre, e vice-versa. No início do experimento foi aplicado um 
questionário para identificar o perfil dos grupos. No início de cada bimestre foi realizada uma prova para verificar o nível de conhecimento prévio dos estudantes sobre o tema de estudo do bimestre. Em cada bimestre foram realizados dois chats e um fórum de discussão no grupo de tratamento. Ao final de cada bimestre foi aplicada uma prova para verificar o desempenho dos estudantes. Foram aplicados testes de médias para identificar se havia diferença entre o desempenho dos grupos, testes de correlação entre as intervenções nos chats e o desempenho dos estudantes para verificar a associação da participação com o desempenho.

Desta forma, o presente estudo teve como objetivo identificar o reflexo do uso de chat e fórum de discussão no desempenho acadêmico. Para isso, uma turma de alunos de Ciências Contábeis foi dividida de forma aleatória em dois grupos. De forma diferente do esperado, um dos grupos teve um desempenho médio inicial estatisticamente superior ao outro. Conforme Gall et al. (2002), quando as notas iniciais não confirmam a hipótese de igualdade entre as médias dos grupos torna-se necessária a comparação da variação entre os desempenhos inicial e final. O desempenho superior, possivelmente, pode ser atribuído a uma característica observável, a inserção no mercado de trabalho, que se refletiu nas notas iniciais diferentes, mesmo com a aleatorização dos grupos. Este resultado encontra respaldo nos trabalhos de Byrne e Flood (2009) e Miranda et al. (2013), que mostram que o conhecimento prévio adquirido no mercado de trabalho tem reflexo positivo no desempenho dos estudantes na graduação. No entanto, quando comparada a variação entre o desempenho no início e o resultado ao final de cada bimestre, observa-se que o desempenho do grupo que utilizou a tecnologia foi superior ao do outro grupo. Com isso, concluiu-se que o desempenho acadêmico pode ser aumentado com o uso das tecnologias, em particular chat e fórum. Deve-se destacar que a variável idade afetou o desempenho dos estudantes: os mais jovens atingiram um desempenho melhor com o uso da tecnologia, e os estudantes com idade superior a 25 anos tiveram pior desempenho no bimestre em que tiveram contato com a tecnologia.

Conclui-se, assim, que o reflexo do uso do chat e fórum de discussão é percebido no desempenho dos estudantes, principalmente, se for considerado o aspecto da idade dos estudantes. No entanto, na interpretação dos resultados desta pesquisa devem-se considerar

algumas limitações. A primeira limitação está relacionada ao fato de os estudantes dos dois grupos apresentaram caraterísticas observáveis diferentes, no que se refere à inserção no mercado de trabalho e à conclusão de curso técnico. Desta forma, é possível que os resultados tenham sido afetados por estes fatos, em que pesem as formas de abrandar seu efeito.

Outra limitação está relacionada às ferramentas de tecnologia da educação usadas no trabalho, visto que o estudo foi centrado em chats e fórum de discussão. $\mathrm{O}$ uso de outras ferramentas pode provocar efeitos distintos, em função de características que cada ferramenta e cada sistema podem oferecer e, por consequência, gerar maior ou menor interesse, provocando facilidades ou dificuldades. Essa limitação está relacionada à possibilidade de generalização dos resultados, conforme exposto por Cohen et al. (2007).

Como principal contribuição, o estudo indica que o uso adequado das tecnologias pode influenciar positivamente o processo de aprendizagem. Por este motivo, os docentes e as instituições precisam estar preparados para o uso das tecnologias, pois a cada ano ingressam estudantes com maior tempo de vivência e mais habilidades no uso das tecnologias.

\section{REFERÊNCIAS}

ABRAMI, P. C.; BERNARD, R. M.; BURES, E. M., BOROKHOVSKI, E.; TAMIM, R. M. Interaction in distance education and online learning: using evidence and theory to improve practice. J Comput High Educ, v. 23, p. 82-103, 2011. 
ALDAMEN, H.; DUNCAN, K. Engagement via web-based quizzes and exam performance in a blended learning intermediate accounting course. Anais European Accounting Association Annual Congress. Paris, França, 2013.

ALDAMEN, H.; AL-ESMAIL, R.; HOLLINDALE, J. Does lecture capturing impact student performance and attendance in an introductory accounting course? Accounting Education, v. 24, n.4, p. 291-317, 2015.

APOSTOLOU, B.; DORMINEY, J. W.; HASSELL, J. M.; REBELE, J. E. Accounting education literature review (2016). Journal of Accounting Education, v. 39, p. 1-31, 2017

APOSTOLOU, B.; DORMINEY, J. W.; HASSEL, J. M.; REBELE, J. E. Acounting education literature review. Journal of Accounting Education, v. 35, p.20-55, 2016.

ATIF, Y. Conversational learning integration in technology enhanced classrooms.

Computers in Human Behavior, p. 1-8, 2012.

BROPHY, J. Motivating Students to Learn. 3. ed., New York: Taylor \& Francis, 2010.

BYRNE, M.; FLOOD, B. Examining the relationships among background variables and academic performance of first year accounting students at an Irish University. Journal of Accounting Education,v. 26, n. 4, p. 202-212, 2009.

CARNEIRO, R.; TOSCANO, J. C.; DÍAZ, T. (Coord.). Los desafíos de las TIC para el cambio educativo. Colección Metas Educativas. Madrid: OEI/Fundación Santillana, 2009.

CHAN, S. H.; SONG, Q.; RIVERA, L. H.; TRONGMATEERUT, P. Using an educational computer program to enhance student performance in financial accounting. Journal of Accounting Education, v. 36, p. 43-64, set. 2016.

CHEN, G. D.; CHANG, C. K.; WANG, C. Y. Ubiquitous learning website: scaffold learners by mobile devices with information-aware techniques. Computers \& Education, v. 50, n. 1, p. 77-90, 2008.

CHIANG, A. C-C.; FUNG, I. P-W. Redesigning chat forum for critical thinking in a problembased learning environment. Internet and Higher Education, v. 7, n. 4, p. 311-328, 2004.

CHIZMAR, J. F.; WALBERT, M. S. Web-Based Learning Environments Guided by Principles of Good Teaching Practice. The Journal of Economic Education, v. 30, n. 3, p. 248-259, 1999.

CHOU, S.; LIU, C. Learning effectiveness in a Web-based virtual learning environment: a learner control perspective. Journal of Computer Assisted Learning, v. 21, n. 1, p. 65-76, 2005 .

COHEN, L; MANION, L; MORRISON, K. Research Methods in Education. 6. ed., New York: Taylor \& Francis e-Library, 2007.

CORNACHIONE JUNIOR, E. B. Tecnologia da educação e curso de Ciências Contábeis: modelos colaborativos virtuais. 2004. Tese de livre-docência, Curso de Pós-graduação em 
Contabilidade e Controladoria, Faculdade de Economia, Administração e Contabilidade, Universidade de São Paulo, São Paulo, SP, 2004.

CORNACHIONE JUNIOR, E. B.; LAWANTO, O.; GITHENS, R. P.; JOHNSON, S. D.The Role of Students' Professional Experience in Online Learning: Analysis of Asynchronous Participation. MERLOT Journal of Online Learning and Teaching, v.8, n. 2, 2012.

DAVIES, J.W.; RUTHERFORD, U. Learning from fellow engineering students who have current professional experience. European Journal of Engineering Education, v. 37, n. 4, p. 354-365, 2012.

FRIEDMAN, D.; SUNDER, S. Experimental methods: a primer for economists. New York: University of Cambridge, 1994.

GALL, M.; GALL, J.; BORG, W. Educational Research. 7. ed. White Plains, New York: Longman, 2002.

HAVNES, A.; SMITH, K.; DYSTHE, O.; LUDVIGSEN, K. Formative assessment and feedback: Making learning visible. Studies in Educational Evaluation, v. 38, n. 1, p. 21-27, 2012.

HOLTZBLATT, M.; TSCHAKERT, N. Expanding your accounting classroom with digital video technology, Journal of Accounting Education, v. 29, p.100-121, 2011

HOU, H. T. Analyzing the behavioral differences between students of different genders, prior knowledge and learning performance with an educational MMORPG: A longitudinal case study in an elementary school. British Journal of Educational Technology, v. 44, n. 3, p. 85-89, 2013.

JENA, P. C. Effect of Technology Based Learning Environment on Academic Achievement. Techno LEARN, v. 1, n. 2, p. 221-229, 2011.

LIST, J. A.; SADOFF, S.; WAGNER, M. So you want to run an experiment, now what? Some simple rules of thumb for optimal experimental design. Experimental Economics, v. 14, n. 4, p. 439-457, 2011.

LUCKESI, C. C. Avaliação da aprendizagem na escola: reelaborando conceitos e recriando a prática. Salvador: Malabares Comunicação e Eventos, 2005.

MAGALHÃES, F. A. C.; ANDRADE, J. X. Exame vestibular, características demográficas e desempenho na universidade: em busca de fatores preditivos. In: Congresso USP de Controladoria e Contabilidade, 2006. Anais... São Paulo: USP, 2006.

McKECHNIE, J.; DUNLEAVY, K.; HOBBS, S. Student employment and its educational impact: a Scottish study. Scottish Educational Review, v. 37, n. 1, p. 58-67, 2005.

McLEOD, S.; DAWSON, S.; BERG L. Using online chat to enhance peer learning while on fieldwork placements. International Journal of Innovation in Science and Mathematics Education, v. 8, n. 1, 2002. 
MIRANDA, G. J.; LEMOS, K. C. S.; PIMENTA, A. S. O.; FERREIA, M. A. Determinantes do Desempenho Acadêmico na Área de Negócios. In.: Encontro de Ensino e Pesquisa em Administração e Contabilidade, 4, 2013. Anais... Florianópolis: ANPAD, 2013.

MORRIS, M.; BURNETT, R. D.; SKOUSEN, C.; AKAABOUNE, O. Accounting education and reform: A focus on pedagogical intervention and its long-term effects. The Accounting Educators' Journal, n. 25, p. 67-93, 2015.

NOVAK, J. D. Learning, Creating, and Using Knowledge: concept maps as facilitative tools in schools and corporations. New York: Taylor \& Francis, 2010.

OLIVER, M.; HARVEY, J. What does 'impact' mean in the evaluation of learning technology? Educational Technology \& Society, v. 5, n. 3, p. 18-26, 2002.

SAVAGE, S. J. The Effect of Information Technology on Economic Education. The Journal of Economic Education, v. 40, n. 4, p. 337-353, 2009.

SCHRUM, L.; LEVIN, B. B. Leading 21st-century schools: Harnessing technology for engagement and achievement. Thousand Oaks, CA: Corwin Press, 2010.

SLAVIN, R. E. (2002). Evidence-based education policies: transforming educational practice and research. Educational Researcher, v. 31, n. 7, p. 15-21, 2002

SOIN, D. Challenges of Information and Communication Technology in Student's Motivation and Learning. Techno LEARN: An International Journal of Educational Technology, v. 1, n. 2, p. 205-213, 2011.

STRANG, K. D. How can discussion forum questions be effective in online MBA courses? Campus-Wide Information Systems, v. 28, n. 2, p. 80-92, 2011.

SUNKEL, G. (2009). Las TIC en la educación en América Latina: visión panorámica. In: R. Carneiro, J. C. Toscano, \& T. Díaz. (Coord.). Los desafíos de las TIC para el cambio educativo (p. 29-43). Colección Metas Educativas. Madrid: OEI/Fundación Santillana, 2009.

TAS, E. A new web designed material approach on learning and assessment in science education. Energy Education Science and Technology Part B: Social and Educational Studies, v. 3, n. 4, p. 567-578, 2011.

TRIOLA, M. F. Introdução à estatística. Rio de Janeiro: LTC, 2005.

ZHAO, Y.; LEI, J.; YAN, B.; LAI, C.; TAN, H. S. What makes the difference? A practical analysis of research on the effectiveness of distance education. Teachers College Record, v. 107, n. 8, p. 1836-1884, 2005. 